\title{
The effect of parental wealth on children's outcomes in early adulthood
}

\author{
Eleni Karagiannaki ${ }^{1}$
}

Received: 28 February 2013 / Accepted: 28 March 2017 / Published online: 28 April 2017

(C) The Author(s) 2017. This article is an open access publication

\begin{abstract}
This paper uses data from the British Household Panel Survey to examine the relationship between parental wealth and three child outcomes in early adulthood. Parental wealth is found to have a very strong positive correlation with children's degree-level qualification attainment at age 25. This correlation is stronger at below-the-median wealth levels and remains strong after controlling for a wide range of confounding family characteristics. There is also evidence of a positive correlation between parental wealth and children's employment probability and earnings. However, for both labour market outcomes the parental wealth gradient is rather weak and for the employment outcome the effect is largely mediated by children's education.
\end{abstract}

Keywords Educational attainment · Employment · Earnings · Equality of opportunity · Intergenerational transmission $\cdot$ Wealth

\section{Introduction}

While the existence of a positive relationship between family background and children's outcomes is a well-established finding (Blanden et al., 2004; Jännti and Jenkins, 2015; Chevalier and Lanot, 2002; Chevalier et al., 2005; Ermisch and Francesconi, 2001), the characteristics of the intergenerational transmission process and the extent to which this relationship is causal is an issue of ongoing debate. In the educational attainment literature, for example, several studies find that family fixed effects such as parental education are more important than family economic resources in explaining children's education, suggesting that credit constraints are relatively unimportant (Cameron and Heckman, 1998; Carneiro and Heckman, 2002; Cameron and Taber, 2004; Carneiro and Heckman, 2003).

Eleni Karagiannaki

e.karagiannaki@1se.ac.uk

1 Centre for Analysis of Social Exclusion, London School of Economics, London, England 
On the other hand, others show that the family economic resources have some strong causal effects, supporting the view that financial constraints significantly affect educational attainment (Krueger, 2003; Belley and Lochner, 2007).

The majority of studies in the intergenerational transmission literature have used family income to approximate family economic resources. The standard practice in this literature, in order to minimize the measurement error and the transitory fluctuations in single-year income measures, has been to use multi-year average family income measures. These measures, despite being successful in reducing the measurement error in income data and in approximating permanent income, neglect a very important component of family economic resources - namely, parental wealth. This omission can be quite problematic given that families may use both income and wealth to provide educational and other resources to their children. Furthermore, a number of studies have shown that the correlation between wealth and permanent income is relatively low, which suggests that even multi-year measures of income are poor proxies for wealth and by extension for total economic resources available to children (Conley, 1999). Therefore, by ignoring wealth the effect of the total family economic resources on children's outcomes may be understated (Lovenheim, 2011). Consider education, for example. Although wealth may affect children's education in similar ways to income, its effects may operate over and above income for several reasons. First, wealth may provide families additional financial resources which may allow parents to live in more expensive areas with high performing schools or to fund private education (either in the form of private schooling or in the form of top-up tuition for children educated in the state sector) and other education-enhancing activities and goods (e.g. music lessons, sporting and cultural activities, computers, books etc). ${ }^{1}$ Beyond compulsory schooling, parental wealth may also provide families with the additional resources to fund further or higher education (for example fees, subsistence expenses or housing) or allow the student to devote their time to study rather than take on term-time employment. The importance of the latter effects depend on the extent to which there are binding credit constraints, whereby limited access to credit markets translates into higher costs of funding higher education for low wealth families. In addition, wealth can insure families against the adverse effects of income shocks (e.g. due to unemployment, illness or family breakup), reducing their negative effects on children. Furthermore, the sense of economic security that wealth provides may increase parents' willingness to undertake educational investments. Beyond these purely financial considerations, parental wealth may affect the academic achievement of a child through its impact on parents' and children's aspirations and expectations (although it should be stressed that the relationship may also run in the opposite direction, i.e. from aspirations and expectations to wealth).

Since education is one of the most important determinants of labour market success, any positive effects that parental wealth has on children's education may translate into labour market advantage. The labour market advantages associated with parental wealth may extend well beyond education. For example, parental wealth may allow children to sustain longer and more costly job search strategies which could result in better job matches, ensuring both more secure employment and higher wages. Alternatively parental wealth may allow access to better jobs through connections and social networks or may provide the necessary capital for business start-ups, influencing children's self-employment prospects.

\footnotetext{
${ }^{1}$ For evidence on the relationship between school and neighbourhood quality and house prices in the UK, see Gibbons and Machin (2003, 2006).
} 
Finally, parental wealth can be used to fund training or other employment enhancing activities or may allow people to pursue riskier career paths which can lead to better jobs and higher earnings.

Recognising the importance of wealth as a central component of family economic resources, a small but growing, mostly US, literature has recently started to investigate the effects of parental wealth on children's outcomes, focusing mainly on children's educational outcomes. These studies provide strong empirical evidence of a positive link between parental wealth and educational achievement, both in terms of schooling outcomes during childhood (Loke and Sacco, 2010; Zhan and Sherraden, 2003), ${ }^{2}$ and in terms of postsecondary educational attainment (Conley, 2001; Pfeffer and Hällsten, 2012; Lovenheim, 2011). The magnitude of the estimated effects is quite substantial. For example, for the US, Conley (2001) showed that doubling parental wealth increases the conditional probability of going to college after graduating from high school by 8.3 per cent, and the probability of graduating once enrolled in college by 5.6 per cent. More recently, Lovenheim (2011), exploiting an exogenous change in housing wealth in the US, found that the rise in housing values during the 2000s significantly increased children's college enrollment, especially among low income families: for every $\$ 10,000$ increase in housing wealth for a low income family the chances of the child going to college increased by 5.7 percentage points. Pfeffer (2011) and Pfeffer and Hällsten (2012) identified similar strong links between parental wealth and children's post-secondary educational attainment for Germany and Sweden, two countries which are characterized by a more generous welfare system than the US. In addition to post-secondary educational attainment, Pfeffer (2011) and Pfeffer and Hällsten (2012) explored the correlation between parental wealth and children's occupational status attainment. Both studies suggest that after taking into account the influence of parental wealth on children's education, parental wealth has a limited influence on children's occupational status attainment in Germany and Sweden, but its influence remains strong in the US.

This paper extends the existing literature on the role of parental resources on children's outcomes in three ways. First, it examines the association between parental wealth during adolescence and a wider range of outcomes in early adulthood (i.e. at age 25) than previous research to give a more comprehensive picture of the potential effects of parental wealth. The outcomes that I examine are the probability that an individual has attained degree level or above qualifications, the probability of being in employment (as opposed to either being unemployed or out of the labour force) and earnings. To the best of the author's knowledge, it is the first time that the latter two outcomes are analysed in this literature. Our results, therefore, will add to the scarce literature on the association between parental wealth and labour market outcomes which up to now have focused on occupational status attainment (Pfeffer, 2011; Pfeffer and Hällsten, 2012). Secondly, in addition to documenting the relationship between total net worth and children's outcomes, I examine whether different types of wealth (net housing vs. net financial wealth) affect different outcomes in different ways, which, to date, has been studied only for some early educational outcomes. Disaggregating by different types of wealth, I aim to provide evidence on the relative importance of different mechanisms linking parental wealth and children's outcomes. The working hypothesis is that the effect of housing wealth reflects more closely the long-term effect of family background whereas the effect of financial wealth captures the financial aspects of the associations and their impact on the immediate well-being of the family. Finally, the paper

\footnotetext{
${ }^{2}$ Studies which examine the effect of parental wealth on schooling outcomes during childhood also include (Orr 2003; Williams Shanks 2007; Yeung and Conley 2008 and Zhan 2006).
} 
extends the existing literature by providing the first estimates of the relationship between parental wealth and children's outcomes in the UK. The UK, along with the US, Italy and France is characterised by low intergenerational earnings mobility (Corak, 2006; Blanden, 2013) and is among the countries where low parental education and low socio-economic status have a very strong impact on children's under-achievement in the education system (Hanushek et al., 2011; OECD, 2010). Previous research on intergenerational transmission in the UK, hampered by the shortage of data on wealth, has focused almost exclusively on parental income and parental education. Yet, household wealth in the UK is substantially more unequal than other family background characteristics and therefore may have strong intergenerational effects.

This paper takes advantage of the long panel dimension and the availability of household wealth data in the British Household Panel Survey to investigate the relationship between parental wealth (measured during adolescence) and three children's outcomes in early adulthood. In line with evidence from other countries, I find that parental wealth has a very strong positive correlation with children's degree-level qualification attainment. This correlation remains strong when controlling for a number of family background factors. However, the estimated effects are highly non-linear, implying far larger impacts at belowthe-median than above-the-median wealth levels. Since lower wealth households are more likely to be credit constrained this non-linearity suggests that the wealth gradient is partly driven by credit constraints. Analysis of the two wealth sub-components shows that housing wealth (which I hypothesise captures the effect of longer-term family background factors) has stronger effects than financial wealth. While the estimates of the models employed in the paper cannot be given a causal interpretation, the statistically significant coefficient of financial wealth is again an indirect indication that credit constraints may play some role in the higher educational decisions of low wealth households. I also find that parental wealth is positively correlated with employment and earnings. As with educational attainment, the estimated effects of wealth on both outcomes are strongest and significant only at the lower half of the parental wealth distribution. For the employment outcome, the estimated size of the effect is small and gets further reduced and turns insignificant when education is added to the model. This suggests that the advantage associated with high levels of parental wealth is largely mediated through the effects of parental wealth on children's education. The effects of parental wealth on children's earnings are also rather small but unlike the employment outcome the estimated effects remain significant when education is included in the model.

The rest of the paper is organised as follows. The next section discusses the data and the sample used in the paper. Section 3 lays out our empirical specifications while Section 4 discusses the representativeness of the sample used in the analysis. Section 5 moves on to present the results, examining first the relationship between parental wealth and higher (degree-level) educational attainment and subsequently the relationship between parental wealth and the two labour market outcomes (employment probability and earnings). Concluding remarks are contained in Section 6.

\section{Data and sample construction}

As mentioned in the introduction, the data used in this paper come from the British Household Panel Survey (BHPS). The BHPS is a household multi-purpose longitudinal survey which was conducted annually from 1991 to 2008. Its original sample consisted of a nationally representative sample of approximately 5500 households containing a total of over 
10,000 individuals. In 2008 the BHPS came to an end but BHPS sample respondents were invited to join the new Understanding Society survey and many of them have chosen to do so.

One advantage of the BHPS for the purpose of this paper is that, in addition to rich data on a range of socio-economic characteristics of each household member, it includes annual information on the value of housing assets owned by the respondents and the value of any outstanding mortgage on these assets (both for primary residence and investment real estate). In addition in waves 5, 10 and 15 the BHPS collected information on whether the respondents had any financial wealth holdings falling in three broad asset categories (i.e. savings, investments and debt) and the value of assets in each of these categories. Using information on financial assets and liabilities along with information on self-reported data on housing assets and debt I construct a continuous measure of total household net worth for 1995, 2000 and 2005. Because there is a high rate of non-response in financial asset holdings data and to avoid dropping households (and introducing non-random bias), I impute financial wealth holdings for respondents who either do not report the value of their asset holdings at all or give a banded answer for their asset holdings (Appendix I provides further details).

In addition to wealth availability, a second advantage of the BHPS for our analysis is that it allows us to follow children of BHPS sample members throughout the panel (even when they leave the parental home) and to link their outcomes in adulthood to their parents' resources. For this paper I selected a sample of children aged 12-18 in 1995 (i.e. when household net worth data were first collected in BHPS) who were observed in the panel when they were 25 years old and whose parents' wealth in 1995 was not missing. ${ }^{3}$ A problem with the parental wealth measure used in this paper is that one of its major components i.e. net financial wealth includes a large number of imputed observations. The number of imputed observations depended on the sub-component, but the share of imputed observations for our sample overall was approximately 30 per cent. Although this seems relatively high, it is reassuring to note that less than 5 per cent of the sample had all three components imputed. ${ }^{4}$

As shown in Fig. 1 the distribution of parental wealth is highly skewed: the average value of net worth of the poorest 5 per cent of parents in 1995 was less than $-£ 10,000$ while that of the wealthiest 5 per cent was almost $£ 500,000$ (expressed in 2005 prices using the Retail Price Index). In most parts of the distribution, except from the very top, the main component of net worth was housing wealth. Financial wealth made up a much smaller share of the total and was considerably more concentrated at the upper tail of the distribution than housing wealth. As shown in Table 1, the Gini coefficient of parental wealth was around 0.62 , which was slightly higher than that of net housing wealth (0.58) but substantially lower than that of net financial wealth (0.97). By comparison, note that the Gini coefficient of equivalised household disposable income in the same year in the UK was 0.33 .

\footnotetext{
${ }^{3}$ The restriction in the age range is necessary because we need to observe individuals while living with their parents in order to observe their parents' wealth. Similarly, we select our sample from wave 5 (rather than from waves 10 or 15 ) because only wave 5 provides the necessary time window to observe children's outcomes in early adulthood.

${ }^{4}$ Sensitivity analyses excluding imputed observations produced somewhat higher estimates than the estimates based on the full sample, but the main conclusions of the analysis were not affected. Although the higher estimates derived based on the restricted sample may reflect that imputed wealth is more susceptible to measurement error, differences across the two samples precludes any firm conclusions, especially given that the sample with imputed financial wealth is non-random (since households with positive financial wealth tend to be wealthier).
} 


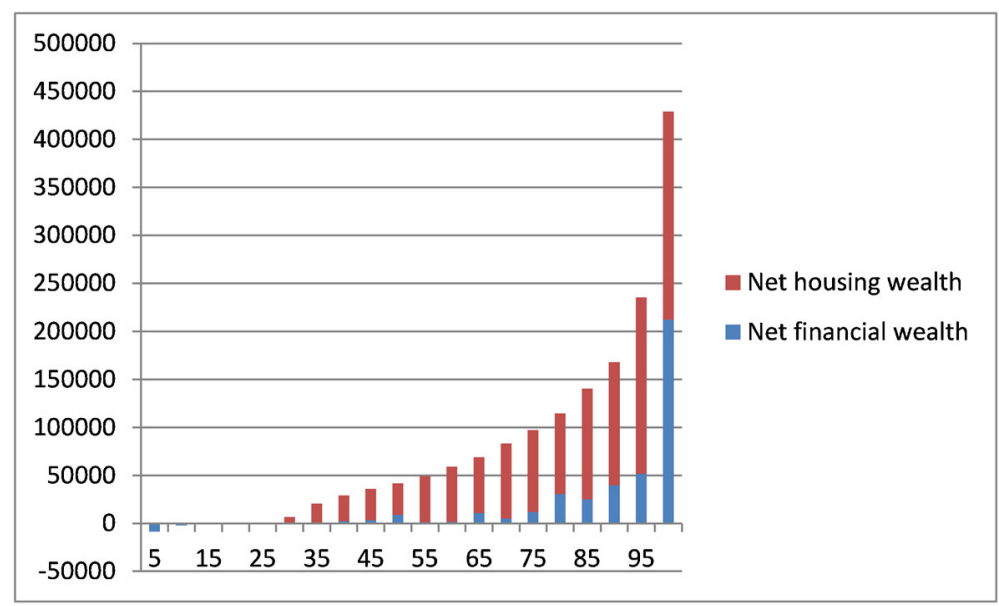

Fig. 1 Average net worth by wealth vigintile broken down into net financial and net housing wealth

\section{Empirical specifications}

The general formulation of the models used in the paper relates each outcome for a child who grew in a family $i$ (i.e. the probability that the individual has attained first or higher degree qualifications, the probability of being in employment and earnings) to parental wealth $\mathrm{W}_{i}$. For the educational and the employment probability outcomes I estimate a series of probit models similar to those specified in Eqs. 1 and 2 respectively and for earnings I estimate a series of OLS models similar to Eq. 3:

$$
\begin{array}{r}
\operatorname{Prob}\left(\mathrm{H}_{i}=1\right)=\Phi\left(\mathrm{X}_{i} \beta+\alpha \mathrm{W}_{i}\right) \\
\operatorname{Prob}\left(\mathrm{E}_{i}=1\right)=\Phi\left(\mathrm{X}_{i} \beta+\alpha \mathrm{W}_{i}\right) \\
1_{\mathrm{ny}_{i}}=\mathrm{X}_{i} \beta+\alpha \mathrm{W}_{i}+\varepsilon_{i}
\end{array}
$$

where $\Phi$ in Eqs. 1 and 2 denotes the standard normal cumulative distribution function (c.d.f.). $\mathrm{H}_{i}$ in Eq. 1 is a dichotomous variable which equals one if respondent $i$ has attained first or higher degree qualifications by age $25 ; \mathrm{E}_{i}$ in Eq. 3 is a dichotomous variable which equals one if respondent $i$ was in employment at age 25 (either as an employee or selfemployed). $\operatorname{lny}_{i}$ in Eq. 3 is the natural logarithm of respondents' hourly earnings and $\varepsilon_{i}$ is an i.i.d. error term that includes omitted determinants of $y$, with zero mean and constant variance. ${ }^{5}$ In all equations, $\mathrm{X}_{i}$ is a vector which controls for child's and parent's characteristics. The parameter of interest in all models is $\alpha$ i.e. the coefficient on parental wealth $\mathrm{W}_{i}$. Given the descriptive nature of the analysis employed in the paper, this coefficient is likely to overstate the causal effects of parental wealth on children's outcomes if there exists parental attributes that are correlated with both parental wealth and children's outcomes. As I discussed in the previous section, our parental wealth measure is defined as the sum of net financial and net housing assets of the parents in 1995. Although this measure excludes some important components of household wealth such as pension assets and business wealth

\footnotetext{
${ }^{5}$ The gross hourly earnings variable is derived from respondents' usual gross pay per month, their normal weekly working hours and their usual paid overtime working hours.
} 
Table 1 The distribution of parental net worth and its two main components
Note: Author's calculation based on data from BHPS. Parental wealth is defined as the sum of net financial and net housing wealth of the parents as in 1995 . All monetary values are expressed in 2005 prices
Distributional statistics

\begin{tabular}{ll}
\hline Parental wealth & \\
Mean & 77,000 \\
Median & 46,000 \\
$25^{\text {th }}$ percentile & 3,000 \\
$75^{\text {th }}$ percentile & 106,000 \\
$90^{\text {th }}$ percentile & 187,000 \\
$\%$ with negative net worth & 16.8 \\
$\%$ with zero & 3.9 \\
Gini & 0.62 \\
Parental financial wealth & \\
Mean & 19,000 \\
Median & 1,200 \\
$25^{\text {th }}$ percentile & -500 \\
$75^{\text {th }}$ percentile & 13,000 \\
$90^{\text {th }}$ percentile & 48,000 \\
$\%$ with negative net financial wealth & 33.7 \\
$\%$ with zero & 4.5 \\
Gini & 0.97 \\
Parental housing wealth & \\
Mean & 58,000 \\
Median & 41,000 \\
$25^{\text {th }}$ percentile & 0 \\
$75^{\text {th }}$ percentile & 85,000 \\
$90^{\text {th }}$ percentile & 135,000 \\
$\%$ with negative net housing wealth & 1.4 \\
Gini & 26.0 \\
Obs. & 0.58 \\
\hline & 492 \\
\hline
\end{tabular}

it represents a large share of the total family wealth. Moreover, compared to the excluded wealth components, the wealth components included in this measure are those that are more readily accessible to consume or to convert to other assets and therefore more relevant for the analysis of this paper.

The rationale for using 1995 net worth instead of wealth measures from later waves is that it is less susceptible to reverse causality bias than measures of wealth in 2000 and 2005 (given that, in these waves, outcomes would have been already realised for a large proportion of our sample and therefore we would not be able to tell whether the estimated associations run from parental wealth to children's outcomes or vice versa). Moreover, the fact that wealth in later waves may be endogenous to children's outcomes means that I cannot use a multi-year average wealth measures to mitigate the effects of measurement error.

As I have already mentioned in the introduction, in addition to exploring the overall effect of parental wealth, I also address the question of whether different types of wealth influence children's outcomes in different ways. Since different types of assets have a varying degree 
of liquidity, I hypothesize that their contribution to observed outcomes may be different. Assets that are more liquid (such as saving accounts, stocks and bonds) can be used more easily for a family's immediate well-being compared to more illiquid types of assets (such as housing assets). Housing assets on the other hand, may reflect more closely the longerterm effects of family background and, in the particular case of educational attainment, the effect of parental housing choices on the early educational attainment of their children (through their association with neighbourhood and school quality). Therefore, in investigating the correlation between parental wealth and degree attainment, I hypothesize that financial wealth would capture more closely the effects of short-run financial constraints on post-secondary educational choices while housing wealth would reflect the longer-term cumulative effect of family background (including the effect of parental housing choices) on children's educational attainment. I have no a priori strong expectations as to whether financial or housing wealth would have a differential effect on children's employment and earnings.

For each outcome I estimate three specifications. For the educational attainment outcome, the baseline specification includes controls for parental wealth as well as a set of primary controls for the age and the region of residence of the parents in wave 5 (to control for the correlation between these two variables and parental wealth) ${ }^{6}$, the child's gender, the number of siblings (which may be important in determining how resources are allocated within the household) and a set of cohort dummies. The second specification adds controls for parental education (for both parents), the logarithm of parental income (averaged over all waves that the parents were observed in the panel to smooth out transitional variations in income), parental unemployment status (measured by a dummy variable indicating whether the respondent lived in a household headed by an unemployed person in any of the waves when the respondent was 13-18 years old), and a set of dummy variables indicating parental tenure status (i.e. whether the parents were owner-occupiers, social tenants or private renters). By including controls for parental income and parental education I aim to determine whether there is any additional advantage associated with wealth over and above the influence of parental income and education. On the other hand, the parental unemployment and parental tenure status variables are aimed at separating the disadvantage associated with low levels of wealth from the confounding influence of these two aspects of family disadvantage. The third specification adds controls for the number of books in the childhood home as indicated by the respondent in wave thirteen (captured by three dummy variables indicating whether the respondent rated the books in childhood home from birth up to the age of 10 - as lots of books, quite a few or not many) as well as controls for the quality of local schools as self-reported by the respondents' mother in wave eight (measured by four variables indicating whether the mother rated the quality of local schools as excellent, very good, fair or poor). The variables indicating the number of books in the childhood home are included as proxies of the extent to which the child experienced a cognitively enhancing home environment and as a partial measure to control for unobserved attributes of the parents. The quality of local schools variables, on the other hand, are included in the model as proxies for the motivation of neighbourhood choice and are used to control for the possible endogeneity of parental housing choices (and by extension housing wealth) with respect to children's education. Given the positive correlation between house prices and school and neighbourhood quality (see Gibbons and Machin, 2003, 2006) any

${ }^{6}$ Parental age is measured as the maximum of the mother's and father's age in wave 5. 
correlation between parental wealth and children's education may simply reflect the correlation between parental housing choices and parents' aspirations for their children's education.

For the employment and earnings outcomes, the baseline specification includes parental wealth and the set of primary controls which are included in the degree attainment model as well as two additional controls for respondents' marital status and number of children. In the earnings equation, the baseline specification also includes controls for the respondent's tenure in the present job, whether the job is full-time or part-time and whether the respondent lives in London (to control for average differences in wages between London and the rest of the country). The second specification adds controls for various other family background characteristics (i.e. parental education, parental income, parental unemployment and tenure status) and is intended to capture the independent association between parental wealth and the two employment outcomes. The final specification includes controls for children's education and aims to capture the extent to which the effect of parental wealth is mediated through children's education. For the earnings equation, I also estimate specifications which control for selection in employment (see discussion in Section 5.2). In all specifications, parental wealth is entered as a spline function with a knot at the 50th percentile of the parental wealth distribution in order to allow for non-linearities in its effects. Table Appendix 7 in the appendix provides summary statistics of the variables used in the various specifications and models.

\section{Sample restrictions and sample representativeness}

As I mentioned in Section 2, the sample used in this paper is restricted to children aged 12-18 in 1995 who were observed in the panel when they were 25 years old and had nonmissing parental wealth in 1995. Overall among the 1,107 children aged 12-18 in 1995, 1,049 were living with their parents (natural, adoptive or step-parents). Among those 936 had non-missing data on parental wealth (i.e. about 90 per cent of all children who lived with their parents) and 492 gave full interviews at age 25. This is our main estimation sample, although as I discuss below, the size of the sample used in the various models is reduced slightly due to missing values in some of the outcomes and covariates.

In all regressions, I exclude children whose mother was not observed in the panel (17 observations) or with missing information on mother's education (8 observations). I do not select children on the basis of availability of paternal education as the number of children with missing information on father's education is rather high, which would raise some serious selection issues (given that a high proportion of these children come from lone parents households). Instead, in the specifications which control for paternal education, I include two additional dummy variables indicating whether paternal education is missing and whether the father is not observed in the panel.

The sample in the employment and earnings models also excludes respondents who are long-term sick and disabled (14 observations) - to avoid the potential negative effect of children's health on parental wealth - and respondents in full-time education. For the earnings analysis the sample is further restricted to employees with non-missing data on either usual pay or working hours. Clearly, the severe reduction of the sample raises the issues of small sample size and the potential lack of representativeness of the data as there may be selection problems with respect to availability of wealth data and more importantly non-random attrition. 
To examine the representativeness of the sample, Table Appendix 8 presents summary statistics of selected variables used in our analysis for our sample and for three subsamples of the full sample of children aged 12-18 in 1995: those who left the panel at an earlier age; those with missing information on parental wealth; and those who remained in the panel but did not give full interviews at age 25. Reassuringly, there are no statistically significant differences across samples in the proportion of children that have achieved A-level qualifications at age 18, which suggests that non-random attrition is not severe. Compared to children who left the panel, the parents of the children in our sample have higher educational attainment levels (the proportion of respondents in our sample whose fathers and mothers have A-level or above qualifications is respectively 12 and 3 percentage points higher than in the sample who left the panel). Also compared to children who left the panel, the children in our sample have around 12-13 per cent higher parental wealth and income levels. While differences in parental wealth and maternal education are not statistically significant, there are statistically significant differences in paternal education and parental income. However, differences in paternal education between the two samples are related to the higher proportion of children in the sample who left the panel with missing information on paternal education rather than a higher proportion of children whose fathers had lower educational qualifications (below O-level qualifications). It is difficult to determine the source of the differences in parental income, but it is likely that this is related to the fact that for children who left the panel, this variable was constructed by averaging income over fewer years (reflecting the lower attachment of their families in the panel). Reassuringly, a similar proportion of children who remained in the panel and those who have left have missing information on wealth (11 and 10 per cent respectively), suggesting that there is no correlation between wealth availability and attrition status that could seriously undermine our results.

For most variables, differences between our sample and the sample of children with missing parental wealth are either small or statistically insignificant. Paternal education is the only variable for which there are statistically significant differences between the two sub-samples. However, these differences are once again related to the higher proportion of children in the sample with missing parental wealth for whom paternal education is missing, rather than a higher proportion of children in this sample whose fathers had lower educational qualifications. Overall, the results allow us to conclude that there are no severe selection problems due to attrition and missing wealth information.

\section{Results}

In Table 2 I begin the exploration of the relationship between parental wealth and children's outcomes by presenting how each outcome varies across parental wealth quartile groups. For the highest educational qualification attainment outcome, the statistics of the table show a threefold rise in the probability of degree level attainment between the bottom and second lowest parental wealth quartile group and a further threefold increase in the same probability between the second lowest and the top wealth group. For the two employment outcomes, differences are much smaller but still important, with a gap in average earnings between the bottom and the top wealth group of around 20 per cent and a difference in the employment probability of around 22 percentage points. A closer inspection of the statistics shows that the employment disadvantage associated with low levels of parental wealth is mainly concentrated at the lower part of the distribution and mainly reflects the relatively 
Table 2 The distribution of children's outcomes at age 25 across different parental wealth quartiles

\begin{tabular}{llllll}
\hline & \multicolumn{2}{l}{ Parental wealth quartile group } & \multirow{2}{*}{ Overall } \\
\cline { 2 - 3 } & Bottom quartile & $2^{\text {nd }}$ quartile & $3^{\text {rd }}$ quartile & Top quartile & \\
\hline Educational attainment (\%) & & & & & \\
GCSE level or below & 38.2 & 23.6 & 12.2 & 6.5 & 20.1 \\
At least one A level & 44.7 & 49.6 & 42.3 & 35.8 & 43.1 \\
Degree level or above & 4.9 & 15.5 & 37.4 & 48.0 & 26.4 \\
Still at school & 4.1 & 0.8 & 0.0 & 0.8 & 1.4 \\
Missing & 8.1 & 10.6 & 8.1 & 8.9 & 8.9 \\
Labour market status (\%) & & & & & \\
Self-employed & 0.8 & 3.3 & 2.4 & 4.9 & 2.9 \\
Employed & 61.8 & 81.3 & 80.5 & 81.3 & 76.2 \\
Unemployed & 12.2 & 3.3 & 4.9 & 5.7 & 6.5 \\
Maternity leave & 0.0 & 0.0 & 0.8 & 1.6 & 0.6 \\
Family care & 14.6 & 8.1 & 5.7 & 2.4 & 7.7 \\
In full-time education & 2.4 & 2.4 & 3.3 & 3.3 & 2.9 \\
Long-term sick-disabled & 8.1 & 0.8 & 2.4 & 0.0 & 2.9 \\
Government training scheme & 0.0 & 0.8 & 0.0 & 0.0 & 0.2 \\
Other & 0.0 & 0.0 & 0.0 & 0.8 & 0.2 \\
Gross hourly pay & & & & & 9.0 \\
Mean & 8.0 & 8.0 & 9.6 & 10.0 & 492 \\
Median & 7.6 & 7.6 & 9.0 & 9.5 & 123 \\
Obs. & 123 & 123 & 123 & & \\
\hline
\end{tabular}

Notes: The sample used in the analysis includes all children aged 12-18 years old with non-missing parental wealth in 1995 who are observed at age 25. Parental wealth is defined as total net worth (the sum of net financial and net housing wealth) of the parents as in 1995. Source: Author's calculations based on BHPS waves $1-18$

high proportion of children in the bottom wealth group who are long-term sick or in family care. Overall, while these results are suggestive of a positive correlation between parental wealth and children's adult outcomes, we need to move beyond these simple comparisons to refine the estimates. This observation is particularly relevant given that a number of variables are known to be correlated with wealth and some of these could also be correlated with children's outcomes (for evidence on the degree of correlation between parental wealth and parental income and parental education see Table Appendix 9). Hence, I now turn to a multivariate approach in order to examine the influence of parental wealth net of the effect of other correlated family background factors. Results for the educational outcome models are discussed in Section 5.1 and for the two employment outcomes models in Section 5.2.

\subsection{Parental wealth and educational attainment}

Table 3 reports results from probit regressions of the determinants of children's degreelevel qualification attainment. As discussed in Section 3 in all specifications parental wealth is entered as a spline function with a knot at the 50th percentile of the parental wealth 
Table 3 Marginal effects from probit models predicting the probability of degree-level (or above) attainment by age 25
(1)
(2)
(3)
(4)
(5)
(6)

Splines of parental net worth

Wealth $<$ median

$\begin{array}{lll}\mathbf{0 . 0 8 3}^{* * * *} & \mathbf{0 . 0 6 1}^{* * * *} & \mathbf{0 . 0 5 9} * * * \\ (5.90) & (2.77) & (2.71) \\ \mathbf{0 . 0 0 6}^{* *} & 0.003 & 0.002 \\ (2.48) & (1.14) & (0.97)\end{array}$

Splines of net financial wealth

Financial wealth $<$ median

$-\quad \quad-$

0.118

0.144*

0.145*

Financial wealth $>$ median

- $\quad-$

(1.856)

(1.870)

$\begin{array}{lll}0.004 & 0.002 & 0.002\end{array}$

Splines of housing wealth

$$
-
$$$$
-
$$

(1.298) (0.564)

(0.682)

Housing wealth $<$ median

Housing wealth $>$ median

Mother's ed. (ref.<O-level)

O-level

0.071
$(1.07)$
$0.210 * * *$
$(3.58)$

$-$

$\mathbf{0 . 0 8 0}^{* * *} \quad \mathbf{0 . 0 5 8}^{* *} \quad \mathbf{0 . 0 5 5}^{* *}$

A-level or above

$$
\text { (3.58) }
$$

$-$

$\begin{array}{lll}(5.163) & (2.057) & (2.022) \\ \mathbf{0 . 0 0 9} * * & 0.003 & 0.002 \\ (2.050) & (0.740) & (0.373)\end{array}$

Father's ed. (ref. $<\mathrm{O}$ level)

O-levels

$$
0.234 * *
$$

$0.254 * *$

$$
\text { (2.17) }
$$

(2.40)

0.104

0.097

(1.56)

(1.45)

0.098

0.079

(1.22)

(1.01)

0.028

0.019

(0.42)

(0.30)

0.057

0.033

$(0.71)$

(0.869)

$(0.522)$

$-$

$0.208^{* * *}$

$0.187^{* * *}$

(3.559)

(3.215)

Parents were unemployed

$\begin{array}{ll}- & 0.028 \\ - & (0.42)\end{array}$

(0.30)

Public Housing

$$
\begin{array}{ll}
-0.037 & -0.026 \\
(-0.36) & (-0.24) \\
-0.052 & -0.068 \\
(-0.36) & (-0.53)
\end{array}
$$

$0.235^{* *} \quad 0.256^{* *}$

(2.198)

(2.441)

$0.117 * \quad 0.108$

(1.755) (1.605)

$0.109 \quad 0.095$

(1.353) (1.201)

$0.017 \quad 0.010$

(0.256) (0.149)

Number of books in home

Quite a few

$\begin{array}{lllll}- & -0.034 & - & - & -0.042 \\ - & (-0.69) & - & - & (-0.860) \\ - & -0.037 & - & - & -0.048 \\ - & (-0.48) & - & - & (-0.659) \\ & & & & \\ - & -0.084 & - & - & -0.077 \\ - & (-1.31) & - & - & (-1.178)\end{array}$


Table 3 (continued)

\begin{tabular}{lllllll}
\hline & $(\mathbf{1})$ & $\mathbf{( 2 )}$ & $\mathbf{( 3 )}$ & $\mathbf{( 4 )}$ & $\mathbf{( 5 )}$ & $\mathbf{( 6 )}$ \\
\hline Fair & - & - & $-0.162^{* * *}$ & - & - & $-0.157 * * *$ \\
& - & - & $(-2.98)$ & - & - & $(-2.882)$ \\
Poor & - & - & $-0.188^{* * *}$ & - & - & $-0.189 * * *$ \\
& - & - & $(-3.99)$ & - & - & $(-3.975)$ \\
Sample size $N$ & 417 & 417 & 417 & & 417 & 417 \\
Log-Likelihood & -206.540 & -192.513 & -187.305 & -206.437 & -191.260 & -185.974 \\
Pseudo-R-squared & 0.175 & 0.231 & 0.252 & 0.175 & 0.236 & 0.257 \\
\hline
\end{tabular}

Note: All models exclude respondents (i) with missing information on mother's education (ii) still in fulltime education and (iii) those with missing information on education. Additional variables included in all models are: parental age, a set of dummies indicating the region of residence of the parents in wave 5, a set of year dummies when the child was 25 years old, child's gender, the number of siblings, an indicator of whether the father was missing, and whether father's education was missing. Wealth is measured in $£ 10,000$. Standard errors are adjusted to account for repeated observations on siblings and half-siblings. Corresponding $\mathrm{t}$-statistics are in parentheses. $* * *$ indicates coefficient statistically significant at the $1 \%$ level, $* *$ at the $5 \%$ level and * at the $10 \%$ level

distribution. As shown in Table Appendix 10 this spline function produces the smallest AIC than alternative functional forms of wealth (including linear, log-linear and wealth dummies). For ease of interpretation, the table reports marginal effects rather than coefficients. The marginal effects of the parental wealth variables from the baseline model in column (1) suggest that there is a strong positive correlation between parental wealth and the probability of degree-level qualification attainment. The marginal effects are larger for below-the-median than above-the-median wealth levels, implying non-linear effects: an additional $£ 10,000$ increase of parental wealth at below-the-median wealth levels is associated with 8.3 per cent increase in the probability of degree-level attainment, an effect which is more than 13 times as large as the estimated impact for above-the-median wealth levels. Since lower wealth households are more likely to be credit constrained this non-linearity suggests that the wealth gradient is partly driven by credit constraints. The inclusion of other measures of family socio-economic status in column (2) (i.e. parental education, income, unemployment and tenure status) reduces the marginal effect of the below-themedian wealth variable by 25 per cent and that of the above-the-median wealth variable by 50 per cent and turns its effects insignificant. Results from specifications in which each family background characteristic was included sequentially, show that the reduction of the marginal effect of the above-the-median wealth variable was mainly driven by the inclusion of controls for parental education. This suggests that parental education, which is widely believed to be closely related to (unobserved) parenting quality, explains more of the predicted probability of degree-level attainment in above-the-median than below-the-median wealth levels, which is likely to be because parents with higher education also have above the median wealth levels. The inclusion of controls for the number of books in the childhood home and the quality of local schools in column (3), has a very small impact on the marginal effect of the below-the-median wealth variable but reduces the marginal effect of the above-the-median wealth variable by more than a third, which suggests that much of the effects of wealth at above the median wealth levels can be explained by local school quality and the quality of home environment. 
Columns (4)-(6) of Table 3 presents results from a series of probit models which include separate controls for net financial and net housing wealth. Similarly to total net worth, the estimates on both measures suggest a positive non-linear relationship with degree-level attainment, with stronger effects for below-the-median than for above-the-median wealth levels. The statistically significant effects at low levels of financial wealth are consistent with the assumption of the existence of credit constraints on post-secondary education for children from low wealth households. For housing wealth, on the other hand, the effects can be interpreted as reflecting the longer-term effect of family background factors possibly related (among others) to parental housing choices and their impact on the cognitive and non-cognitive development of their children.

To get a sense of the magnitude of the estimated effects, in Table 4 I present the predicted probabilities of degree-level attainment for different percentiles of total parental wealth and its two sub-components (note that differences in the levels and the distribution of the three wealth variables preclude any direct comparisons of their marginal effects). The predicted probabilities in the top panel of Table 4 are calculated setting total parental wealth at its value in different wealth percentiles while keeping all other characteristics at their sample values and then averaging the predicted probabilities across all observations. The predicted probabilities in the middle and the bottom panels of Table 4 show the predicted probabilities at different values of financial and housing wealth respectively and are calculated in a similar way.

Using the estimates from the baseline model, I find that an increase in total parental wealth from the $25^{\text {th }}$ to the $50^{\text {th }}$ percentile is associated with 29 percentage points increase in the probability of degree-level attainment, while a further increase to the $75^{\text {th }}$ and the $90^{\text {th }}$ percentiles with a further 4 and 14 percentage points increase respectively (however, note that none of the latter two changes are significant). In the model with the full set of controls, the predicted probabilities at below-the-median wealth levels increase slightly (suggesting that some of the educational disadvantage associated with low levels of wealth, as predicted by the baseline model, reflects the effect of correlated measures of parental disadvantage) while those at above-the-median wealth levels decrease (again slightly). Overall, differences in the predicted probabilities at below-the-median wealth levels are reduced, but remain strong (note the non-overlapping confidence intervals between the predicted probabilities at most wealth levels below the median), while most of the differences at above-the-median wealth levels are eliminated. According to the estimated effects from this model, an increase in parental wealth from the $25^{\text {th }}$ to the $50^{\text {th }}$ percentile is associated with a 21 percentage point increase in the probability of degree-level qualification attainment, while a further increase to the $75^{\text {th }}$ percentile is associated with just a further 1 percentage point increase. By comparison, according to the same model, an increase in parental income from the $25^{\text {th }}$ to the $75^{\text {th }}$ percentile (from $£ 27,200$ to $£ 45,800$ ) is associated with just 5 percentage points increase in the probability of attaining degree-level qualifications (from 24 to 29 per cent) - which is less than a quarter of the estimated impact from an equivalent increase from the $25^{\text {th }}$ to the $75^{\text {th }}$ percentile of the parental wealth distribution. The marginal effects of maternal education from the same model suggest that the children whose mother has qualifications at A-level or above have about 19 percentage points higher probability of achieving degree-level qualifications compared to children whose mother has qualifications at O-level or below (each group is roughly a third of the sample). Looking at the predicted probabilities of the two wealth sub-components, we see that while the patterns in terms of housing wealth are very similar to those in terms of total net worth, those in terms of financial wealth are considerably weaker and are only significant at very low wealth levels. The statistically significant effects of financial wealth suggests that financial constraints may play an important role in higher education choices for some low wealth financially-indebted households. 


\subsection{Parental wealth and labour force participation and earnings}

Columns (1)-(3) in Table 5 report results from a series of probit models of the determinants of the probability of being in employment. The baseline model in column (1), suggests that there is a statistically significant positive relationship between parental wealth and the probability of being in employment at below-the-median wealth levels but a substantially smaller and statistically insignificant relationship at above-the-median wealth levels: a $£ 10,000$ increase in parental wealth at below-the-median wealth levels increases the employment probability by 1.9 percentage points while an equivalent increase at above the median wealth levels is associated with only a 0.001 percentage point increase .

The inclusion of controls for other family background characteristics in column (2) leaves the marginal effect of the below-the-median parental wealth variable unchanged but it reduces the magnitude and the significance of the marginal effect of the above-the-median wealth levels even further. The marginal effect of the parental unemployment status in the same model is negative indicating that children whose parents were unemployed have a significantly lower probability of being in employment. On the other hand, the marginal effects of the variable indicating parental tenure status suggest that children of private

Table 4 Predicted probabilities of degree-level attainment at different wealth percentiles for total net worth and for each sub-component of wealth

(1)

Net worth percentile

$$
\begin{aligned}
& 0.062[0.020,0.104] \\
& 0.078[0.034,0.123] \\
& 0.365[0.290,0.439] \\
& 0.404[0.340,0.468] \\
& 0.537[0.425,0.649]
\end{aligned}
$$

(4)

$$
\begin{aligned}
& 0.237[0.170,0.304] \\
& 0.276[0.232,0.319] \\
& 0.293[0.245,0.342] \\
& 0.300[0.252,0.348] \\
& 0.334[0.272,0.395]
\end{aligned}
$$

Net housing wealth

\section{Net financial wealth}

$$
\begin{aligned}
& \mathrm{P} 25=-600 \\
& \mathrm{P} 50=1,000 \\
& \mathrm{P} 75=13,000
\end{aligned}
$$

(2)

(3)$$
\mathrm{P} 10=0
$$$$
\mathrm{P} 25=0
$$$$
\mathrm{P} 50=42000
$$$$
\mathrm{P} 75=86,000
$$$$
\mathrm{P} 95=193,000
$$

$0.108[0.023,0.193]$
$0.124[0.042,0.206]$
$0.342[0.255,0.429]$
$0.359[0.281,0.437]$
$0.417[0.300,0.534]$

(5)

$$
\begin{aligned}
& 0.236[0.173,0.300] \\
& 0.282[0.241,0.323] \\
& 0.303[0.257,0.349] \\
& 0.308[0.262,0.353] \\
& 0.320[0.268,0.372]
\end{aligned}
$$

0.113 [0.026, 0.201]

0.129 [0.045, 0.213]

$0.340[0.255,0.425]$

$0.354[0.279,0.429]$

0.401 [0.293, 0.508]

(6)

$$
\begin{aligned}
& 0.237[0.175,0.299] \\
& 0.283[0.243,0.323] \\
& 0.304[0.258,0.349] \\
& 0.308[0.264,0.353] \\
& 0.323[0.273,0.373]
\end{aligned}
$$

$$
\begin{aligned}
& 0.133[0.026,0.239] \\
& 0.133[0.026,0.239] \\
& 0.333[0.241,0.426] \\
& 0.349[0.265,0.433] \\
& 0.387[0.253,0.521]
\end{aligned}
$$

$0.143[0.035,0.251]$

$0.143[0.035,0.251]$

0.334 [0.246, 0.422]

$0.341[0.263,0.419]$

$0.359[0.239,0.480]$

Note: Predicted probabilities are calculated based on models presented in Table 3. These predicted probabilities are calculated setting parental wealth at different wealth values (corresponding to different wealth percentiles) while keeping all other characteristics at their sample values and then averaging the predicted probabilities across all observations. Confidence intervals are reported in square brackets 
Table 5 Marginal effects from probit models predicting the probability of being in employment and OLS earnings estimates

$\begin{array}{ll}\begin{array}{l}\text { Probit employment } \\ \text { probability }\end{array} & \begin{array}{l}\text { OLS log linear earnings } \\ \text { equations }\end{array}\end{array}$

\begin{tabular}{|c|c|c|c|c|c|c|}
\hline & (1) & (2) & (3) & (4) & (5) & (6) \\
\hline \multicolumn{7}{|l|}{ Splines of parental net worth } \\
\hline \multirow[t]{2}{*}{ Wealth $<$ median } & $0.019 * *$ & $0.019 *$ & 0.009 & $0.022 * *$ & $0.030 * *$ & $0.026 * *$ \\
\hline & $(2.271)$ & $(1.663)$ & $(0.876)$ & (2.315) & $(2.222)$ & (1.995) \\
\hline \multirow[t]{2}{*}{ Wealth $>$ median } & 0.001 & -0.000 & -0.000 & 0.004 & 0.002 & 0.002 \\
\hline & $(0.394)$ & $(-0.056)$ & $(-0.008)$ & $(1.558)$ & $(0.839)$ & $(0.649)$ \\
\hline \multicolumn{7}{|l|}{ Mother's ed. (ref.<O-level) } \\
\hline \multirow[t]{2}{*}{ O-level } & - & 0.021 & 0.019 & - & 0.021 & 0.017 \\
\hline & - & $(0.680)$ & $(0.634)$ & - & $(0.460)$ & $(0.389)$ \\
\hline \multirow[t]{2}{*}{ A-level or above } & - & 0.023 & 0.010 & - & 0.033 & 0.015 \\
\hline & - & $(0.703)$ & $(0.289)$ & - & $(0.802)$ & $(0.370)$ \\
\hline \multicolumn{7}{|l|}{ Father's ed. (ref. $<$ O level) } \\
\hline \multirow[t]{2}{*}{ O-levels } & - & -0.051 & -0.042 & - & 0.046 & 0.028 \\
\hline & - & $(-0.813)$ & $(-0.715)$ & - & $(0.746)$ & $(0.452)$ \\
\hline \multirow[t]{2}{*}{ A-level or above } & - & -0.040 & -0.034 & - & 0.042 & 0.027 \\
\hline & - & $(-0.949)$ & $(-0.847)$ & - & $(0.852)$ & $(0.544)$ \\
\hline \multirow[t]{2}{*}{ Log. of parental income } & - & 0.046 & 0.032 & - & $0.135^{* *}$ & $0.142 * *$ \\
\hline & - & $(1.013)$ & $(0.754)$ & - & $(2.280)$ & $(2.435)$ \\
\hline \multirow[t]{2}{*}{ Parents were unemployed } & - & $-0.086^{*}$ & -0.078 & - & $0.093^{* *}$ & $0.099 * *$ \\
\hline & - & $(-1.648)$ & $(-1.529)$ & - & $(2.088)$ & $(2.120)$ \\
\hline \multicolumn{7}{|l|}{ Parent's tenure in wave 5} \\
\hline \multirow[t]{2}{*}{ Public Housing } & - & 0.030 & 0.012 & - & 0.104 & 0.105 \\
\hline & - & $(0.688)$ & $(0.278)$ & - & $(1.514)$ & $(1.580)$ \\
\hline \multirow[t]{2}{*}{ Rented accommodation } & - & $0.061 * *$ & $0.059 * *$ & - & 0.001 & 0.009 \\
\hline & - & $(2.096)$ & $(2.218)$ & - & $(0.010)$ & $(0.120)$ \\
\hline \multicolumn{7}{|c|}{ Education (ref. GCSE or below) } \\
\hline \multirow[t]{2}{*}{ At least one A-level } & - & - & $0.088 * * *$ & - & - & 0.014 \\
\hline & - & - & $(2.768)$ & - & - & $(0.310)$ \\
\hline \multirow[t]{2}{*}{ Degree or above } & - & - & $0.087 * * *$ & - & - & $0.121 * *$ \\
\hline & - & - & $(2.877)$ & - & - & $(2.091)$ \\
\hline Sample size & 434 & 434 & 434 & 338 & 338 & 338 \\
\hline Pseudo/adjusted-R-squared & 0.264 & 0.300 & 0.326 & 0.181 & 0.197 & 0.213 \\
\hline
\end{tabular}

Note: All models exclude respondents (i) with missing information on mother's education (ii) still in fulltime education (iii) with missing information on education, (iv) who are long-term sick and disabled and (v) in full-time education. In the earnings equations the sample is further restricted to employees with nonmissing data on either usual pay or working hours. Additional controls included in the models are described in Section 3. Standard errors are adjusted to account for repeated observations on siblings and half-siblings. Wealth is measured in $£ 10,000$. Corresponding t-statistics are in parentheses. $* * *$ indicates coefficient statistically significant at the $1 \%$ level, $* *$ at the $5 \%$ level and * at the $10 \%$ level 
renters have a significantly higher probability of being in employment than children of owner-occupiers. This result probably reflects the fact that children from more advantaged backgrounds (such as children of owner-occupiers) are both more likely to pursue higher education and more able to sustain longer job search activities (and therefore to postpone their entry into the labour market) than their counterparts from more disadvantaged backgrounds. Adding sequentially each family background variable (results not shown here), the marginal effect of the below-the-median wealth variable fall slightly when controls for parental unemployment status were added in the model (suggesting that some of the negative effects of parental wealth on employment probability as identified by the baseline model reflects the confounding influence of exposure to unemployment during childhood or adolescence years). However, when controls for parental tenure status were included in the model the marginal effect of the below-the-median wealth variable increased back to the level estimated in the baseline model (reflecting the negative effects of homeownership on employment probability and the positive correlation between homeownership and wealth levels).

Unsurprisingly, children's own education appears to be the most important determinant of their employment status, with the model in column (3) predicting a 9 percentage points higher probability of being in employment for those with degree and those with A-levels or further qualifications than for those with GCSE or below. ${ }^{7}$ Its inclusion in the model turns the marginal effects of the below-the median-wealth variable statistically insignificant. According to the estimates from this model, the predicted employment rate differential between the $10^{\text {th }}$ and the $50^{\text {th }}$ percentile of the parental wealth distribution is around 4 percentage points (which is very similar to the 5 percentage point employment rate differential between married and unmarried people and only slightly lower than the gender differential as estimated by the model with the full set of controls) while the predicted employment rate differential at higher wealth levels is almost negligible (see Table 6).

Columns (4)-(6) of Table 5 report results from a set of models of the determinants of children's log hourly earnings. The estimates from the baseline model in column (4) suggest a positive and statistically significant relationship between parental wealth and children's earnings. Similarly to the employment probability models, the effects are relatively small: an additional $£ 10,000$ increase in parental wealth at below-the-median wealth levels is associated with 0.022 per cent higher earnings and an equivalent increase at above-themedian wealth levels with just 0.004 per cent higher earnings. In the model with the full set of family background controls (column 5), the marginal effects of the below-the-median wealth variable increases by more than a third whereas the marginal effect of the above-themedian wealth variable falls by 50 per cent. The marginal effect of parental income in the same model is positive and statistically significant, suggesting that parental income has an independent positive association with children's earnings. On the other hand, the marginal effects of unemployment status variables are positive, counterintuitively suggesting that children from more disadvantaged backgrounds (i.e. children who lived in households headed by unemployed people) have significantly higher earnings than their counterparts from more advantaged backgrounds (i.e. children who did not live in households by headed

\footnotetext{
${ }^{7}$ The education categories used here are very broad. Previous studies suggested that finer distinction in educational attainment can lead to clearer differences in employment advantage (Smith, et al. 2000).
} 
Table 6 Predicted employment probability and predicted log wages at various wealth percentiles

(1)

\section{Employment probability}

Net worth percentile

$\mathrm{P} 10=-640$

$\mathrm{P} 25=4,000$

$\mathrm{P} 50=46,000$

$\mathrm{P} 75=106,000$

$\mathrm{P} 90=301,000$

Net worth percentile

$\mathrm{P} 10=-640$

$\mathrm{P} 25=4,000$

$\mathrm{P} 50=46,000$

$\mathrm{P} 75=106,000$

$\mathrm{P} 90=301,000$

\section{Log hourly earnings}

(4)

$$
\begin{aligned}
& 2.162[2.103,2.221] \\
& 2.195[2.153,2.237] \\
& 2.265[2.211,2.318] \\
& 2.291[2.250,2.332] \\
& 2.370[2.264,2.476]
\end{aligned}
$$

(2)

(3)

$\begin{array}{lll}0.793[0.729,0.858] & 0.795[0.705,0.885] & 0.829[0.755,0.902] \\ 0.809[0.756,0.861] & 0.811[0.741,0.880] & 0.836[0.778,0.894] \\ 0.890[0.845,0.934] & 0.893[0.843,0.944] & 0.877[0.822,0.932] \\ 0.894[0.856,0.931] & 0.893[0.848,0.937] & 0.877[0.828,0.926] \\ 0.903[0.847,0.960] & 0.891[0.830,0.952] & 0.877[0.810,0.943]\end{array}$

(5)

$\begin{array}{ll}2.147[2.073,2.221] & 2.163[2.090,2.236] \\ 2.192[2.148,2.236] & 2.202[2.158,2.246] \\ 2.285[2.219,2.350] & 2.282[2.218,2.345] \\ 2.299[2.248,2.350] & 2.292[2.243,2.342] \\ 2.342[2.238,2.445] & 2.324[2.224,2.423]\end{array}$

Note: The predicted probabilities in this table are calculated based on coefficients of the models presented in Table 4. Confidence intervals are reported in square brackets

by unemployed people). The inclusion of these variables in the model increased the marginal effect of the below-the-median wealth variable by more than a third, suggesting stronger effects than those identified by the baseline model. This rather counterintuitive result, probably reflects the earlier age at which children from more disadvantaged backgrounds leave full-time education and enter the labour market and illustrates how differences in the shape of the age earnings profiles of children from different socio-economic backgrounds can induce a downward bias in the estimated effects of parental wealth. The inclusion of respondent's education in column (6) (which unsurprisingly has a very strong correlation with children's earnings) reduces the marginal effects of the below-the-median wealth variable by less than 15 per cent. ${ }^{8}$ Overall, according to the estimates from this model, around 15 per cent of the parental wealth effect at below-the-median wealth levels and 40 per cent of the effect at above-the-median wealth levels (not shown in Table 5 due to rounding) as identified by the model in column (5) operate indirectly through its association with children's education.

To get a sense of the magnitude of the effects the second panel of Table 6 shows the predicted log hourly earnings at different parental wealth percentiles (using similar methods as in Table 4). Model 5 predicts a 14 per cent earnings differential between children from the $10^{\text {th }}$ and the $50^{\text {th }}$ percentile and a further 6 per cent differential between children from the $50^{\text {th }}$ and the $90^{\text {th }}$ percentile. These differentials fall to just 11 and 4 per cent respectively

\footnotetext{
${ }^{8}$ Results from extended models, which include separate controls for parental financial and housing wealth (results not shown), suggest that the wealth gradient is stronger in terms of the financial wealth than housing wealth, especially after controls for children's education are added into the model (however a test of equality of the coefficients of these two variables could not be rejected at any conventional level).
} 
in the model with the full set of controls. Although these are rather small effects, there are strong reasons to believe that because the young age of the sample under analysis these are downwards biased estimates of the correlation between parental wealth and children's lifetime earnings. A number of studies in the intergenerational earnings mobility literature have shown that measuring children's earnings at a relatively young age causes a substantial downward bias in the estimates of the intergenerational earnings elasticity (Haider and Solon, 2006; Böhlmark and Lindquist, 2006) - a bias referred to as lifecycle bias.

A further issue of concern is the extent to which the estimates of the earnings models may be biased due to the process of selection into employment. Overall, around 15 per cent of our sample members (excluding those in full-time education and the long-term sick and disabled people) were not in employment at age 25 (the statistics for men and women were 8 and 21 per cent respectively). A sample excluding children not in employment probably causes an under-representation of children from more disadvantaged families. Following the common practice in the literature, I used a Heckman-type selection model in order to examine the extent to which selection into employment biases our results (in order to identify the selection equation I used gender and regional specific unemployment rates). This model produced very similar results to the OLS ones, which allows us to conclude that selection into employment does not seem to cause serious bias in our estimates (results available from the author upon request).

\section{Discussion and conclusions}

This paper has used a linked sample of parents and their adult children from the BHPS to investigate the relationship between parental wealth and three children's outcomes in early adulthood (at age 25). It has been shown that parental wealth has a very strong positive correlation with children's higher educational attainment. The effects of parental wealth have been found to operate over and above the influence of parental income and parental education and remain strong even when controlling for local school quality and number of books in the childhood home to account for unobserved parental attributes and the endogeneity of parental housing choices with respect to children's education. This suggests that the educational disadvantage associated with low levels of wealth does not reflect the impact of other correlated measures of parental disadvantage. Rather it is parental wealth itself that is generating the environment in which children can achieve higher educational attainment. However, the estimated effects imply that the relationship between parental wealth and degree-level qualification attainment is highly non-linear, with far larger impacts at belowthe-median than above-the-median wealth levels. While these results cannot be given a causal interpretation, this non-linearity suggests that the correlation between parental wealth and higher educational attainment is partly driven by credit constraints (since households with below-median wealth levels are more likely to be credit constrained). Results from models which include separate controls for two major wealth components show that housing wealth (which I hypothesise captures the effect of longer-term family background factors) has a far stronger correlation with higher educational attainment than financial wealth. Despite small in magnitude the statistically significant effect of financial wealth is again an indirect indication that credit constraints may play some role in the higher educational decisions of low wealth households. 
It has also been shown that parental wealth has a positive correlation with children's employment and earnings. The effect of parental wealth on children's employment, however, is found to be very small in magnitude and gets further reduced and turns insignificant when children's education is added in the model. This suggests that the advantage associated with higher levels of wealth is largely mediated through its effect on children's education. For earnings, although the effect of parental wealth remains significant when education is added to the model, it is also they are also rather small in magnitude. However, given the young age of the sample used in the paper it is likely that the obtained estimates are downwards biased. Future work evaluating the effects using a bigger sample and at a later age would provide a more robust picture of the magnitude of the potential intergenerational effects in the relationship between parental wealth and lifetime earnings. The expansion of the panel dimension of the BHPS (through the integration of its sample into the Understanding Society survey) could enable this type of analysis.

Although methodological differences do not allow us to make any direct comparisons with other studies, the strong correlation between parental wealth and children's higher educational attainment in the UK appears to be in line with findings for the US, Germany and Sweden. Unfortunately, no previous study examines the association between parental wealth and children's labour force participation and earnings so it is not possible to examine how the estimates in this paper compare with those for other countries.

Overall, the finding that parental wealth is highly consequential for children's educational outcomes - as much or in some cases more than other family background indicators - suggests that wealth is a central component of household resources, and that excluding it from models that attempt to explain children's outcomes may lead to biased estimates. Although it is rather difficult to make policy recommendations without a full understanding of the mechanisms underlying this relationship, the magnitude of the estimated associations and the fact that the strongest effects are identified at low levels of wealth - especially for degree attainment - lend support for policies that promote wealth accumulation at the bottom of the distribution. Such policies could be particularly beneficial for people with low or no wealth and could prove to be particularly effective in reducing inequalities in higher educational attainment.

Before concluding, it should be stressed that while the models employed in the paper controlled for a number of important variables, in common with most studies, the analysis is largely descriptive and as such cannot identify what drives the estimated relationship. While identifying the underlying drivers is very important, the magnitude of the gradient is a first step towards understanding the intergenerational impacts of wealth inequalities. Given the substantial degree of wealth inequality that exists, a better understanding of the magnitude of the relationship between wealth inequality and inequalities in outcomes is important for assessing the intergenerational impacts of wealth inequalities. Focusing only on inheritance as a channel of transmission may be missing some important effects established much earlier in life and may give a misleading representation of the reproduction of wealth inequalities across generations.

Acknowledgments Data for the British Household Panel Survey were made available by the UK Data Archive. The BHPS is copyright Institute of Social and Economic Research (University of Essex, ISER, 2010). Financial support from the Nuffield Foundation and the Growing Inequalities' Impacts (GINI) research project funded under the EU Socio-Economic Sciences and Humanities theme $7^{\text {th }}$ Framework Programme is gratefully acknowledged. The author would like to thank John Hills, Frank Cowell, Howard Glennerster and Abigail McKnight and three anonymous referees for useful comments and suggestions and Tom Sefton for the calculation of housing wealth data in the British Household Panel Survey. All errors and ambiguities are the author's responsibility. 
Open Access This article is distributed under the terms of the Creative Commons Attribution 4.0 International License (http://creativecommons.org/licenses/by/4.0/), which permits unrestricted use, distribution, and reproduction in any medium, provided you give appropriate credit to the original author(s) and the source, provide a link to the Creative Commons license, and indicate if changes were made.

\section{Appendix I}

\section{Details about the definition of net worth and the imputation of financial wealth in BHPS}

In waves 5, 10 and 15 (which correspond to the years 1995, 2000 and 2005) the BHPS included supplementary wealth modules which collected information on whether the respondent had any wealth holdings falling in three broad asset categories i.e. savings, investments and debt. Savings are defined as interest-bearing deposit accounts, investments include other saving products such as shares, unit trusts and Personal Equity Plans, while debt includes a wide range of products including loans, overdrafts and amounts outstanding on mail orders. Respondents are first asked to report whether they have different types of assets falling in each broad asset category and then are asked to report the total amount of their savings, investments and debt and then whether any of their savings, investments and debt are held jointly with someone else. ${ }^{9}$ Respondents who either do not know or refuse to give an answer for their asset holdings are routed to a series of questions that attempt to put bounds on their asset holdings. Given the high rate of non-response in asset holding data and to avoid dropping households (and introducing non-random bias) I impute wealth holdings for households who either do not report or do not give an exact amount for their wealth holdings.

In our imputation I follow Banks et al.'s (2002) methodology and impute missing or banded values in asset holdings using a conditional hot deck imputation method. The imputation is performed at benefit unit level (benefit unit is defined as a single adult or a cohabiting couple and any dependent children) in order to account for joint wealth holdings among household members and to better handle incompatible answers for joint wealth holdings among household members. ${ }^{10}$ For each benefit unit with missing information on asset holdings the hot-deck imputation assigns a random value from all observations with matching characteristics (defined in terms of age and employment status of the head of the benefit unit and by the highest educational attainment of the head or the spouse). For benefit units with banded information, the hot-deck assigns a random value from all observations with matching characteristics whose wealth is in the same wealth range. This imputation procedure is used to impute values separately for each broad asset category (savings, investments and debt). Household financial wealth is then constructed by summing up the financial wealth holdings and debt of all families in the household.

The other main component of household net worth, namely the net housing wealth, is derived by summing up the housing assets of all household members (based on self-reported

\footnotetext{
${ }^{9}$ In 2000 and 2005 respondents reporting sole and joint wealth holdings are asked to specify the amount of sole wealth holdings (and in 2005 the person with whom they hold their wealth jointly).

${ }^{10}$ Similarly to Banks et al. (2002) when two adults in a benefit unit give incompatible answers about their joint wealth holdings I calculate the maximum and minimum value of wealth that reflects the answers of both respondents. The resulting band is then used to impute a continuous wealth value using the conditional hot-deck imputation as described in the text.
} 
data) and subtracting any outstanding mortgage on these assets. Because the problem of non-response in housing assets and liabilities was relatively small, we do not impute observation with missing housing wealth data. Total household net worth for 1995, 2000 and 2005 is then defined by summing up the net housing wealth and net financial wealth holdings of the household. Despite our efforts, wealth is missing for about 10-12 per cent of households in the sample. Missing values in wealth arise mainly due to missing values in housing wealth and to a lesser extent due to missing values in financial wealth (which in turn arise due to missing values in the variables used as matching criteria in the hot-deck matching process).

\section{Appendix II}

Table 7 Descriptive statistics

Various individual, parental and home environment characteristics

\begin{tabular}{lr}
\hline Individual characteristics & \\
Gender (\%) & \\
Male & 47.6 \\
Female & 52.4 \\
Highest educational qualifications at age 25 (\%) & \\
GCSE level or below & 20.1 \\
At least one A level & 43.1 \\
First or higher degree & 26.4 \\
Still at school & 1.4 \\
Missing & 8.9 \\
Whether achieved 5+ GCSEs A*-C & 54.4 \\
Labour market status at age 25 (\%) & \\
Self-employed & 2.9 \\
Employed & 76.2 \\
Unemployed & 6.5 \\
Maternity leave & 0.6 \\
Family care & 7.7 \\
In full-time education & 2.9 \\
Long term sick or disabled & 2.6 \\
Government training scheme & 0.2 \\
Other & 0.2 \\
Homeownership at age 25 (\%) & 27.0 \\
Parental characteristics & \\
Father's education ${ }^{1}$ & \\
No qualifications & \\
&
\end{tabular}


Table 7 (continued)

Notes: The sample includes all children aged 12-18 years old with non-missing parental wealth in 1995 who are observed at age 25. 1. Per cent among those with non-missing information on father's education. 2. Per cent among those with non-missing information on mother's education. 3. Average gross household income of the parents averaged over all waves with available information (expressed in 2005 prices)
Various individual, parental and home environment characteristics

$\begin{array}{lr}\text { Below O-levels some qualifications } & 11.4 \\ \text { O-levels } & 15.0 \\ \text { At least one A level } & 42.7 \\ \text { First or higher degree } & 11.1 \\ \text { Father's education is missing or father is not in }^{2} & 21.5 \\ \text { Mothers education }^{2} & \\ \text { No qualifications } & 24.6 \\ \text { Below O-levels some qualifications } & 12.6 \\ \text { O-levels } & 24.6 \\ \text { At least one A level } & 30.6 \\ \text { First or higher degree } & 7.5\end{array}$

Mother's education is missing or mother is not 5.1 household Parental income ${ }^{3}$

$\begin{array}{ll}\text { Mean } & 38,600 \\ \text { Median } & 35,700 \\ 25^{\text {th }} \text { percentile } & 26,500 \\ 75^{\text {th }} \text { percentile } & 45,800 \\ 90^{\text {th }} \text { percentile } & 57,400\end{array}$

\section{Home environment in childhood home}

Number of books in childhood home

Lots of books $\quad 48.1$

Quite a few $\quad 37.0$

Not many $\quad 12.8$

Missing $\quad 7.1$

Local school quality

Excellent 13.6

Very good $\quad 47.0$

Fair 24.2

Poor $\quad 6.7$

Missing $\quad 8.5$ 


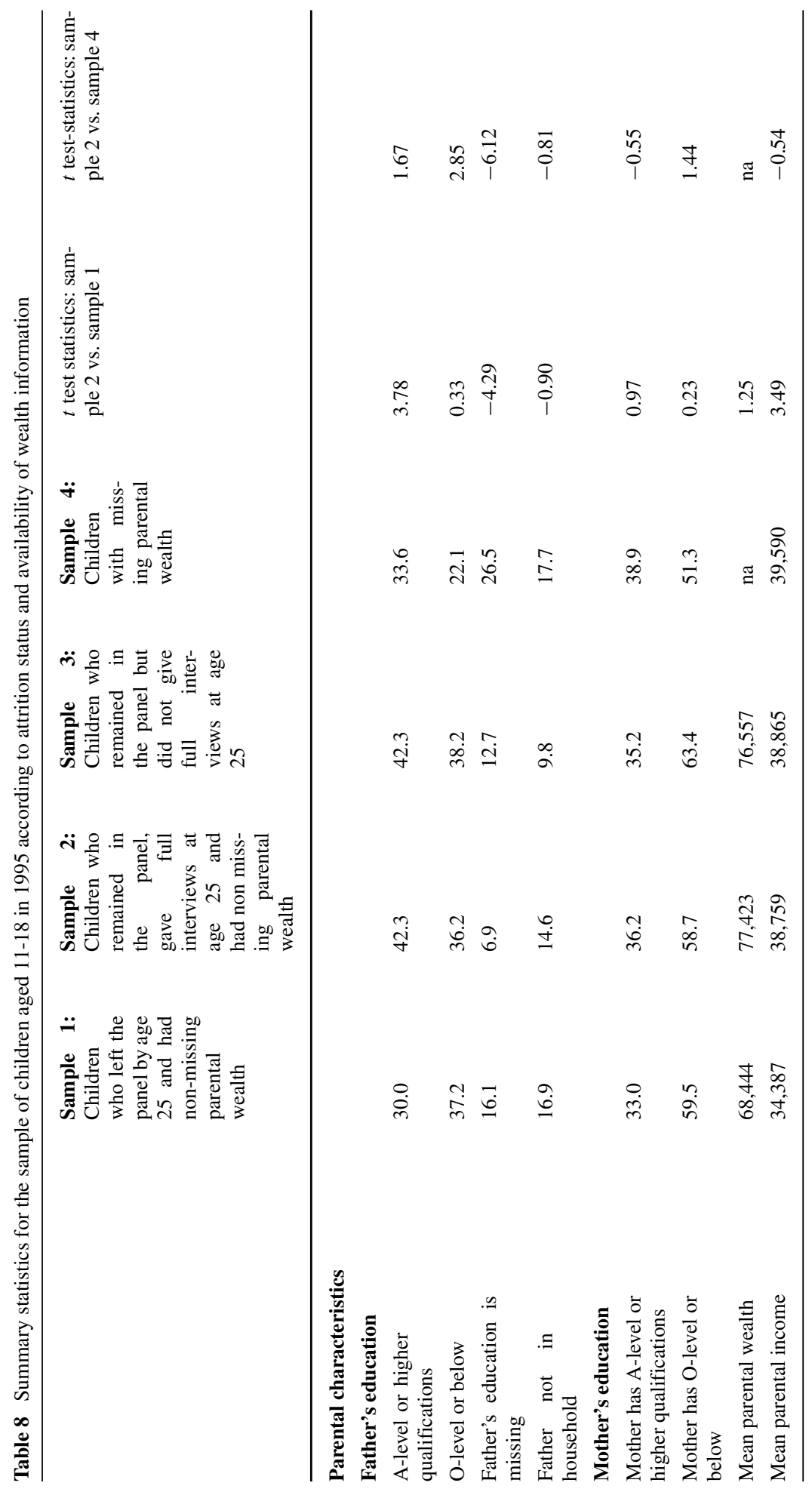




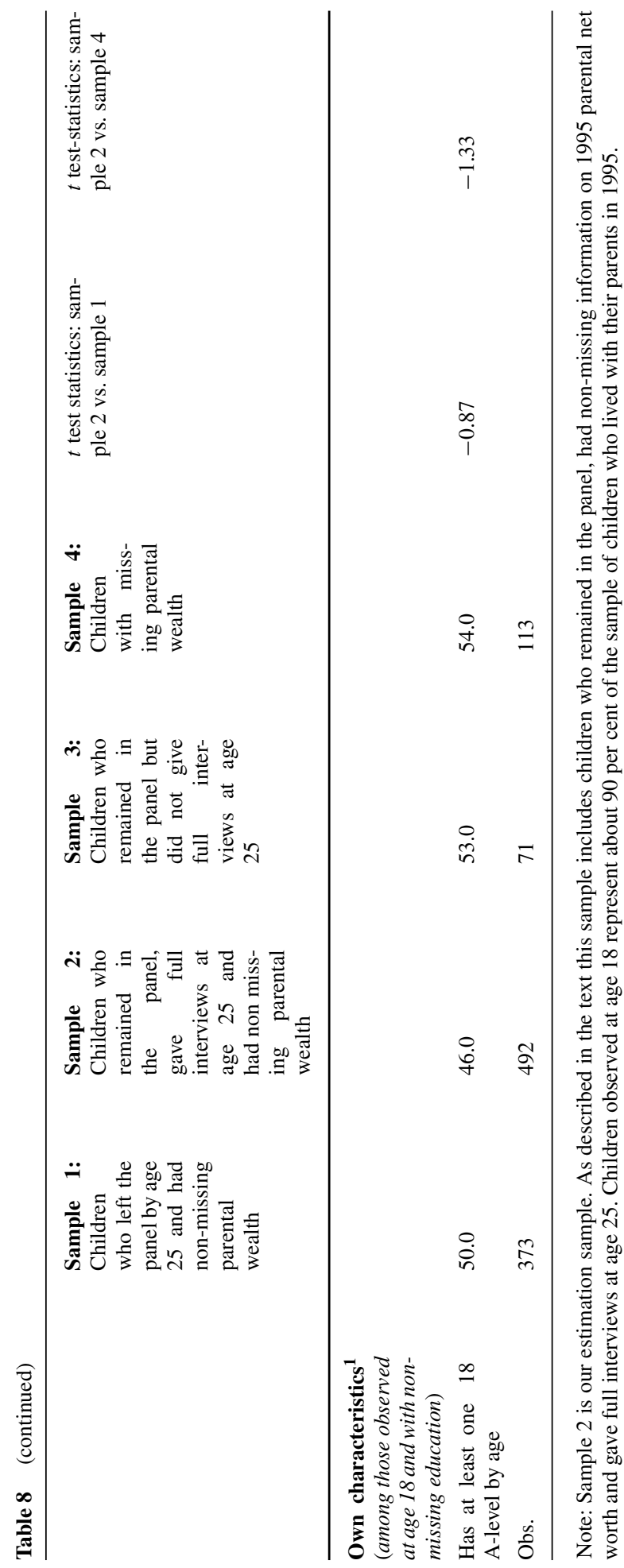


Table 9 Correlation between parental wealth and selected parental background variables

Parental wealth in wave 5 (1995)

Parental income (average over all years parents are observed in the $0.44^{*}$ panel)

Father has degree level or above qualifications

$0.28 *$

Mother has degree level or above qualifications

$0.22 *$

$* \mathrm{p}<0.01$

Table 10 Goodness of fit measures for different functional forms of parental wealth for the educational attainment model

\begin{tabular}{lllll}
\hline & Linear & Wealth dummies & Logarithm & Wealth splines \\
\hline $\mathrm{N}$ & 417 & 417 & 417 & 417 \\
Log-likelihood & -190.250 & -186.727 & -190.892 & -187.305 \\
Pseudo-R & 0.240 & 0.254 & 0.237 & 0.252 \\
AIC & 454.500 & 451.453 & 455.785 & 450.610 \\
BIC & 603.724 & 608.744 & 605.009 & 603.867
\end{tabular}

Note: In addition to parental wealth (in various forms) the models in this table include the variables included in column 3 of Table 4

\section{References}

Banks, J., Smith, Z., Wakefield, M.: The distribution of financial wealth in the UK: Evidence from 2000 BHPS data. IFS WP02/21 Institute for Fiscal Studies (2002)

Belley, P., Lochner, L.: The changing role of family income and ability in determining educational achievement. J. Hum. Cap. 1(1), 37-39 (2007)

Blanden, J., Gregg, A., Goodman, P., Machin, S.: Changes in intergenerational mobility in Britain. In: Corak, M. (ed.) Generational Income Mobility in North America and Europe, pp. 122-46. Cambridge University Press, Cambridge (2004)

Blanden, J.: Cross-country rankings in intergenerational mobility: a comparison of approaches from economics and sociology. J. Econ. Surv. 27(1), 38-73 (2013)

Böhlmark, A., Lindquist, M.J.: Lifecycle Variation between Current and Lifetime Income: Replication and Extension for Sweden. J. Labor Econ. 24(4), 879-896 (2006)

Cameron, J., Heckman, J.: Life cycle schooling and dynamic selection bias: Models and evidence for five cohorts of American males. J. Polit. Econ. 106, 262-333 (1998)

Cameron, S., Taber, C.: Estimation of educational borrowing constraints using returns to schooling. J. Polit. Econ. 112, 132-182 (2004)

Carneiro, P., Heckman, J.J.: The evidence on credit constraints in post-secondary schooling. Econ. J. 112(482), 705-734 (2002)

Carneiro, P., Heckman, J.J.: Human capital policy NBER Working Paper No. 9495. National Bureau of Economic Research, Cambridge MA (2003)

Chevalier, A., Lanot, G.: The relative effect of family characteristics and financial situation on educational achievement. Educ. Econ. 10, 165-182 (2002)

Chevalier, A., Harmon, C., O'Sullivan, V., Walker, V.: The impact of parental income and education on the schooling of their children. IFS WP 05/05 (2005)

Conley, D.: Being Black, living in the red: Race, wealth and social policy in America. University of California Press, Berkeley (1999) 
Conley, D.: Capital for college: Parental assets and postsecondary schooling. Sociol. Educ. 74, 59-72 (2001)

Corak, M.: Do poor children become poor adults? Lessons from a cross-country comparison of generational earnings mobility. In: Creedy, J., Kalb, G. (eds.) Dynamics of Inequality and Poverty Research on Economic Inequality, vol. 13, pp. 143-188. Emerald Group Publishing Limited (2006)

Ermisch, J., Francesconi, M.: Family matters: Impacts of family Background on educational attainment. Economica 68, 137-156 (2001)

Gibbons, S., Machin, S.: Valuing English primary schools. J. Urban Econ. 53(2), 197-219 (2003)

Gibbons, S., Machin, S.: Paying for primary schools: Admission constraints, school popularity or congestion. Econ. J. 116(510), C77-C92 (2006)

Haider, S., Solon, G.: Life-cycle Variation in the association between current and Lifetime Earnings. Amer. Econ. Rev. 96(4), 1308-1320 (2006)

Hanushek, E.A., Ludger, W.: The economics of international differences in educational achievement. In: Hanushek, E.A., Machin, S.E.A., Woessmann, L. (eds.) Handbooks in Economics, vol. 3, pp. 89-200, The Netherlands (2011)

Jännti, M., Jenkins, S.: Income mobility. In: Atkinson, A.B., Bourguignon, F. (eds.) Handbook of Income Distribution, vol. 2, pp. 807-935. Elsevier (2015)

Krueger, A.B.: Inequality, too much of a good thing. In: Heckman, J.J., Krueger, A.B. (eds.) Inequality in America, pp. 1-75. MIT Press, Cambridge, MA (2003)

Lovenheim, F.M.: The effect of liquid housing wealth on college enrollment. J. Labor Econ. 29(4), 741-771 (2011)

Loke, V., Sacco, P.: Changes in parental assets and children's educational outcomes. J. Soc. Policy 40(2), 1-18 (2010)

OECD: A Family Affair: Intergenerational Social Mobility across OECD Countries. In: Economic Policy Reforms Going for Growth (Part II, Chapter 5), Organisation for Economic Cooperation and Development (2010)

Orr, A.J.: Black-white differences in achievement: The importance of wealth. Sociol. Educ. 76, 281-304 (2003)

Pfeffer, F.T., Erikson, R., Jännti, M., Smeeding, T.: Status attainment and wealth in the united states and germany. In: Persistence, Privilege, and Parenting: The Comparative Study of Intergenerational Mobility, pp. 109-138. Russell Sage Foundation, New York (2011)

Pfeffer, F.T., Hällsten, M.: Mobility Regimes and Parental Wealth: The United States, Germany, and Sweden in Comparison. PSC Research Report No. 12-766 (2012)

Smith, J., McKnight, A., Naylor, R.: Graduate employability: Policy and performance in higher education in the UK. Econ. J. 110(464), F382-F411 (2000)

University of Essex: Institute for Social and Economic Research: British Household Panel Survey: Waves 118, 1991-2009 [computer file] 7th edition. Colchester, Essex: UK Data Archive [distributor]. SN: 5151 (2010)

Williams Shanks, T.R.: The impacts of household wealth on child development. J. Poverty 11, 93-116 (2007)

Yeung, W.J., Conley, D.: Black-white achievement gap and family wealth. Child. Dev. 79, 303-24 (2008)

Zhan, M., Sherraden, M.: Assets, expectations, and children's educational achievement in female-headed households. Soc. Serv. Rev. 77, 191-211 (2003)

Zhan, M.: Assets, parental expectations and involvement, and children's educational performance. Child. Youth Serv. Rev. 28, 961-75 (2006) 